\title{
Activity Dependency and Aging in the Regulation of Adult Neurogenesis
}

\author{
Gerd Kempermann \\ German Center for Neurodegenerative Diseases (DZNE) Dresden and Center for Regenerative Therapies \\ Dresden (CRTD), Technische Universität Dresden, 01307 Dresden, Germany \\ Correspondence: gerd.kempermann@dzne.de
}

\begin{abstract}
Age and activity might be considered the two antagonistic key regulators of adult neurogenesis. Adult neurogenesis decreases with age but remains present, albeit at a very low level, even in the oldest individuals. Activity, be it physical or cognitive, increases adult neurogenesis and thereby seems to counteract age effects. It is, thus, proposed that activity-dependent regulation of adult neurogenesis might contribute to some sort of "neural reserve," the brain's ability to compensate functional loss associated with aging or neurodegeneration. Activity can have nonspecific and specific effects on adult neurogenesis. Mechanistically, nonspecific stimuli that largely affect precursor cell stages might be related by the local microenvironment, whereas more specific, survival-promoting effects take place at later stages of neuronal development and require the synaptic integration of the new cell and its particular synaptic plasticity.
\end{abstract}

\begin{abstract}
ge and activity might be considered the two antagonistic key regulators of adult neurogenesis. Whereas adult neurogenesis declines with age (which is at least the common perception), different kinds of "activity" positively regulate adult neurogenesis. A reciprocal interaction between these two mechanisms exists. Aging influences activity, and activity affects aging processes.

Aging is a principal determinant of life and as such cuts across all biological, psychological, and sociological domains. The very essence of aging is difficult to conceptualize because it is a uniquely omnipresent variable. Aging can, thus, only be addressed in a transdisciplinary approach, especially if the consequences of aging on complex brain functions are to be studied. In
\end{abstract}

the context of adult neurogenesis research, "aging" has largely been equaled with the biology of long time scales. Implicit in this understanding is that age-dependent changes essentially reflect a unidirectional development in that everything builds on what has occurred before. In this sense, aging can also be seen as continued or lifelong development. This idea has limitations but is instructive with regard to adult neurogenesis, because adult neurogenesis is neuronal development under the conditions of the adult brain. The age-related alterations of adult neurogenesis themselves have quantitative and qualitative components. So far, most research has focused on the quantitative aspects. But there can be little doubt that qualitative changes do not simply follow quantitative changes (e.g.,

Editors: Fred H. Gage, Gerd Kempermann, and Hongjun Song

Additional Perspectives on Neurogenesis available at www.cshperspectives.org

Copyright (C) 2015 Cold Spring Harbor Laboratory Press; all rights reserved; doi: 10.1101/cshperspect.a018929

Cite this article as Cold Spring Harb Perspect Biol 2015;7:a018929 
in cell or synapse numbers), but emerge on a systems level and above when an organism ages.

The observation that adult neurogenesis is regulated by activity relates to this idea. From a behavioral level down to a synaptic level, activity increases adult neurogenesis. This regulation does not seem to occur in an all-or-nothing fashion but rather influences different stages of neuronal development differently.

To date, the biology of aging has emphasized aspects of molecular and cellular biology, and has looked at entire organisms only if, for example, longevity was studied. With respect to adult neurogenesis, only one multilevel experiment including morphology and behavior has been conducted, and, even in that study, only three time points were investigated (Driscoll et al. 2006). A more complete theory of adult neurogenesis across the life span will require close reference to concepts on many levels of research, including systems biology, behavioral and cognitive neuroscience, and developmental and cognitive psychology.

Recent years have brought fundamentally new insight in how brain function and structure are linked. This mutual interaction is one key meaning of "plasticity." The term "plasticity," despite all of its importance for modern neurobiology and psychology, remains elusive. But the concept is important because it states that one cannot see cognitive function independent of the underlying structure (and also vice versa). In this context, adult neurogenesis has become a topic of particular attraction.

The observation that adult neurogenesis is regulated by activity cannot be considered independent of a functional theory (see Toni and Schinder 2015 for detailed discussion). If "activity" means "functionally relevant activity" (which remains to be proven) the regulation becomes part of the function because learning and structural change are tightly and causally linked. This is what is meant by plasticity: the reciprocal interaction between structure and function. In other words, the functional theory should incorporate the idea of the reciprocal effect of function on neurogenesis, inasmuch as a concept of "regulation" cannot exist without an idea of what the entire process is leading to functionally.

\section{AGE EFFECTS ON ADULT NEUROGENESIS}

Even Altman's first description of adult hippocampal neurogenesis in 1965 contained a paragraph on the noticeable decrease in cell genesis within months after birth (Fig. 1) (Altman and Das 1965). Kaplan later reported that adult neurogenesis would occur in old rodents, but did not include a detailed quantitative analysis (Kaplan and Bell 1984; Kaplan 1985). The first studies to specifically look at age effects on adult neurogenesis came from Seki and Arai (1995) and Kuhn, Gage, and colleagues (1996), and the analogous report for mice in 1998 (Kempermann et al. 1998b). The same year saw Eriksson's groundbreaking study on neurogenesis in aging humans: he presented evidence for adult hippocampal neurogenesis in individuals as old as in their early seventies (Eriksson et al. 1998). Since then, adult neurogenesis is accepted as a lifelong process. The carbon-14 birthdating technique, discussed in detail in Bergmann et al. (2015), has finally revealed that adult hippocampal neurogenesis is actually substantial (Spalding et al. 2013). The data suggested that about one-third of the granule cell population in adult humans shows a very slow turnover. In short-lived animals, such as mice and rats, such turnover has not become evident, and it appears that new neurons that survived the first weeks of their existence would stay for the rest of the life or for at least a very long time (Kempermann et al. 2003). The proportion of one-third of newly born cells is, however, consistent with an estimate from a lineage-tracking study in mice (Ninkovic et al. 2007).

Although the amount of adult neurogenesis in humans turned out to be bigger than assumed (Goritz and Frisen 2012; Spalding et al. 2013), the absolute numbers are still very low. The big question is what the functional contribution of so few new neurons over so long periods can be. Any comprehensive concept has to bring together the acute functional contributions of newly generated, highly plastic neurons and the more-or-less lasting changes they introduce to the network.

Information on age effects on neurogenesis in the olfactory system has not received as much 


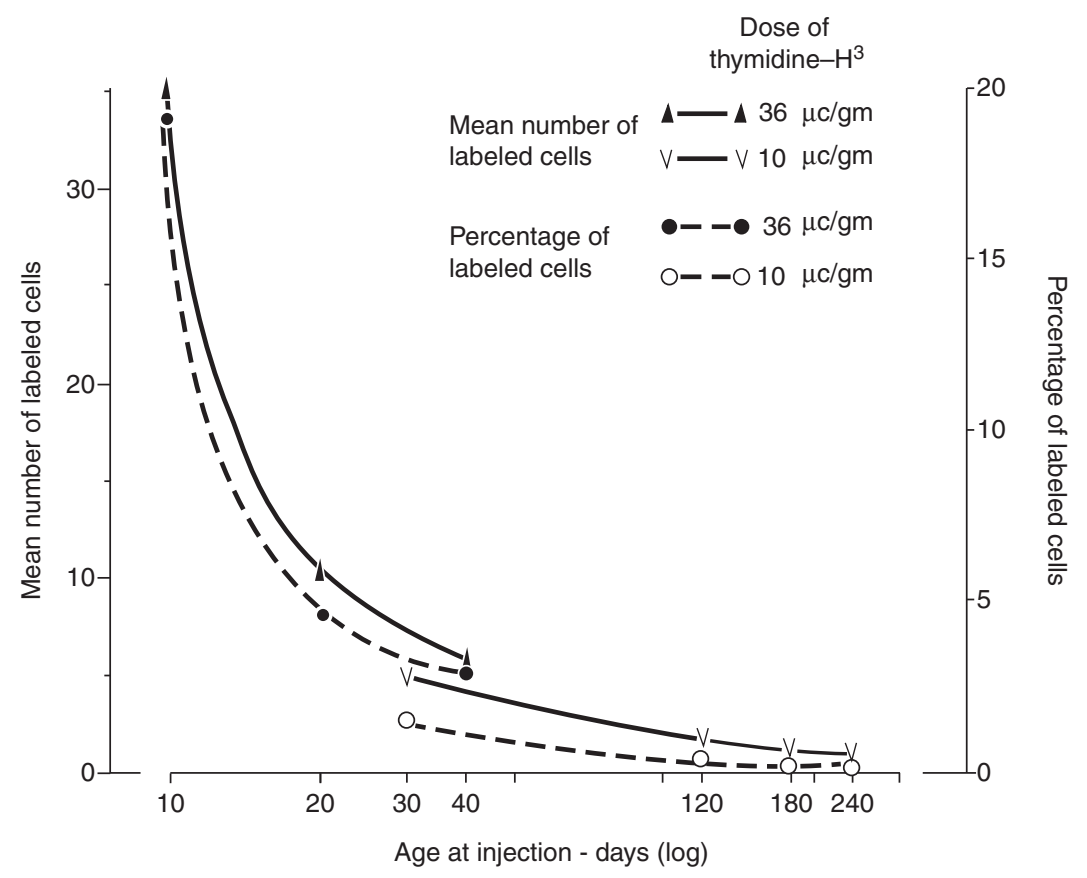

Figure 1. Age effects on adult hippocampal neurogenesis. Even in the inaugural paper of the field, the original description by Altman and Das (1965) of adult hippocampal neurogenesis contained data revealing how strongly postnatal and adult neurogenesis decrease with age. Today, absolute numbers can be assigned to the different time points, revealing that, throughout most parts of the adult life, hippocampal neurogenesis ranges on a minute scale. (From Altman and Das 1965; reprinted, with kind permission, by Joseph Altman and John Wiley and Sons (C) 1965.)

attention as for the hippocampus (but see the review in Brann and Firestein 2014). Although, in 1997, Tropepe, van der Kooy, and colleagues reported that the aging subventricular zone (SVZ) contained fewer precursor cells than in younger rats (Tropepe et al. 1997), only in 2004 was a direct in vivo study published (Enwere et al. 2004). Luo and colleagues finally gave a complete account of the structural and neurogenic changes in the aging SVZ in 2006 (Luo et al. 2006). Ex vivo, precursor cells from the adult SVZ showed longer cell-cycle times with increasing age (Tropepe et al. 1997), but this was questioned by others (Luo et al. 2006).

In both neurogenic systems, aging seems to result in a reduced number of precursor cells, most notably a decline in the number of transiently amplifying cells, and a decrease in cell proliferation (Seki 2002; Garcia et al. 2004; Luo et al. 2006). It is not quite clear whether this is also true for the more quiescent stem cells from which the progenitor cells might reappear if adequately stimulated. Maslov et al. (2004) reported a twofold decrease in the number of putative stem cells in the SVZ (based on the expression of $\mathrm{G}_{1}$-phase-specific proliferation marker $\mathrm{Mcm} 2$ that presumably allows a distinction between the relative quiescent and the more proliferative transient amplifying cells) and a corresponding reduction in the yield of neurospheres that could be obtained from the aging SVZ. Luo et al. (2006) did not find a decrease in astrocyte-like cells in the SVZ or even an increased number of astrocytes touching the ventricular lumen. It is exactly this contact that has previously been identified as a hallmark of the putative stem cells in the SVZ (Doetsch et al. 1997).

Encinas and colleagues (2011) have proposed that the hippocampal potential for neurogenesis becomes exhausted with age, the precursor cells turning into nonneurogenic astrocytes. As a caveat, however, the study has been 
performed under conditions in which the mice were not challenged to lead an active life. The decrease might just represent the consequence of negligence as in the old saying "use it or lose it."

A key facet of aging might be inflammatory processes. These often relate to microglial activation (Gebara et al. 2013). Pharmacological inhibition of microglia with minocycline increased neurogenesis (Monje et al. 2003; Kohman et al. 2013) and exercise reduced microglial counts (Ehninger and Kempermann 2003; Gebara et al. 2013). The exact role of microglia in this context still needs to be elucidated (Su et al. 2014).

The age-related loss is not uniform across the population of precursor cells. Sox1-positive cells, for example, which form a subset of the hippocampal precursor cells, are comparatively well preserved (Kuipers et al. 2014).

For rodents, the decrease in adult hippocampal neurogenesis appears to be almost hyperbolical, with a very strong decline early in life and a rather low but persistent level for the remainder of the life span (Ben Abdallah et al. 2010). Barker and Wojtowicz suggested that, in other rodent species, the decrease might be more linear (Barker et al. 2005). This remains to be confirmed in larger comparative experiments, but indicates that genetic factors determine the impact of aging on adult neurogenesis.

Although aging is often called a strong (or even the strongest) negative regulator of adult neurogenesis, the term "regulator" is actually problematic in the context of aging. It is undisputed that neurogenesis decreases with age and, in old age, adult neurogenesis occurs at only a small fraction of the level in early adulthood; but the decline does not seem to be "regulated" but rather the by-product of many age-related changes of other sorts (Kempermann 2011). This range of impact makes aging a particularly complex variable.

\section{MECHANISMS UNDERLYING THE AGE-RELATED DECLINE IN ADULT NEUROGENESIS}

Besides the presence or absence of the precursor cells, the decline of neurogenesis in the senes- cent brain might be caused by a loss of extrinsic signals, a reduced responsiveness of the aging precursor cells to normal signaling, or both. Senescence of the precursor cells in the neurogenic zones has, to date, only been investigated in one study; an increase of p16INK4a, a cyclindependent kinase inhibitor linked to cellular senescence, was associated with the age-related loss of precursor cells in the SVZ but not in the hippocampus (Molofsky et al. 2006). This regional discrepancy with respect to cellular senescence might be attributable to the different cellular composition and stem-cell features in the two neurogenic regions (Seaberg and van der Kooy 2002) but requires further work.

One characteristic of stem cells is the expression of telomerase that prevents telomere shortening under sustained proliferation (Lee et al. 1998). Telomerase activity has been linked to the regulation of adult neurogenesis, but no study focusing specifically on age effects has been published (Caporaso et al. 2003). However, at least in an animal model of schizophrenia, exercise reconstituted telomerase activity to physiological levels, possibly implying that control of this aging mechanism is somehow involved in the antagonism of age and activity (Wolf et al. 2011).

Adult neurogenesis requires a specific microenvironment, the so-called niche, which provides the signals that are needed to maintain and control the proliferation and differentiation of the precursor cells (Palmer et al. 2000; Mercier et al. 2002; Seki 2003). Precursor cells and their niche form a functional unit. The neurogenic niche consists of the precursor cells and their progeny, glia and endothelial cells, possibly immune cells and macrophages, and an extracellular matrix, surrounded by a shared basal membrane. Within the neurogenic niche, cell-cell contacts, paracrine signaling of neurotransmitters, neurotrophic factors, and growth factors, as well as synaptic contacts, control neurogenesis. It has been proposed that the decline in precursor cell activity in the aging hippocampus is a result of increased precursor cell quiescence caused by changing niche properties (Hattiangady and Shetty 2008). One underlying concept is that the niche structure is important for homeostatic maintenance of neurogenesis 
and that, during aging, this interdependence might get out of balance (Silva-Vargas et al. 2013).

One instrumental factor that has been found to decrease is WIP1, which is upstream of Dickkopf 3 in the Wnt pathway. Transgenic up-regulation of WIP1 prevented impaired neuronal differentiation in aged mice (Zhu et al. 2014). Conversely, the related protein Dickkopf 1 increases with age and its loss prevents the age-dependent decline. Regulatable deletion of Dickkopf 1 in the precursor cells increased both self-renewal and maturation of the progeny (Seib et al. 2013). Related to this has been the observation that Wnt-mediated regulation of mitotic factor survivin is changed in the aging niche and might explain part of the effect (Miranda et al. 2012).

Also, changes in growth factor levels might underlie changes in neurogenesis as a consequence of disease or aging. Neurotrophic factors, growth factors, and their receptors are abundant during development and decline with age (Wise 2003; Shetty et al. 2005; Chadashvili and Peterson 2006). Growth factors have a strong influence on precursor cell proliferation and neuronal differentiation and, thus, might be important mediators of cellular plasticity in aging (Cameron et al. 1998; Kwon 2002; Hattiangady et al. 2005; Shetty et al. 2005). The aged mouse brain retains the capacity to respond to the neurogenesis-stimulating effects of growth factors (Lichtenwalner et al. 2001; Jin et al. 2003; Sun et al. 2005).

Although some factors decrease with age, others, such as cell-cycle regulator transforming growth factor $\beta 1$ (TGF- $\beta 1$ ), might increase. Overexpression of TGF- $\beta 1$ in old mice inhibited the proliferation of early precursor cells (Buckwalter et al. 2006).

The age-related increase in serum glucocorticoids has been proposed as the main culprit for the age-dependent loss of new neurons (Cameron and McKay 1999) (we will discuss them below), when a synthesis is attempted between the findings of age dependency and activity effects on adult neurogenesis.

Serum factors of young mice infused into aged mice "rejuvenated" the niche; among the specifically identified factors was GDF11, which also positively affected blood vessels in the brain (Katsimpardi et al. 2014). These results highlight the complex interaction of cell-intrinsic and -extrinsic mechanisms, both with respect to the aging process itself and also the paths toward its (partial) reversal. Increasingly, inflammatory factors are recognized as critical in this context, mostly suggesting that age is associated with more "inflammation," but the picture is far from clear (Mendelsohn and Larrick 2011; Villeda and Wyss-Coray 2013).

\section{PRINCIPLES OF ACTIVITY-DEPENDENT REGULATION OF NEUROGENESIS}

Brain development originates from a genetic program that unfolds during the fetal period and early postnatally, and becomes increasingly influenced by regulatory influences from the outside world. Although the general pattern of brain anatomy is genetically controlled and not affected by activity, the details of network formation, especially on the synaptic level, are activity dependent.

Similarly, the general flow of adult neurogenesis is determined genetically. The general pattern of neurogenic regulation brings about the idea that regulation of adult neurogenesis might be divided into a less-specific phase of precursor cell proliferation and a specific phase of selective survival (Kempermann et al. 1997a, 2004a, 2006; Winner et al. 2002; Kronenberg et al. 2003). In a genetic study, we have found that most of the net neurogenic regulation is determined by the control of survival and not of the expansion phase (Kempermann et al. 2006). The fine regulation on the quantitative and presumably the qualitative level, however, occurs in coordination with parameters of activity. Both cell proliferation and survival are influenced by or even depend on activity.

With regard to activity on a behavioral level, one can grossly distinguish between physical exercise and cognitive stimulation (Fig. 2). Physical exercise robustly increases the proliferation of precursor cells in the hippocampus (but not in the olfactory bulb) (Brown et al. 2003), thereby expanding the population of progenitor 
G. Kempermann
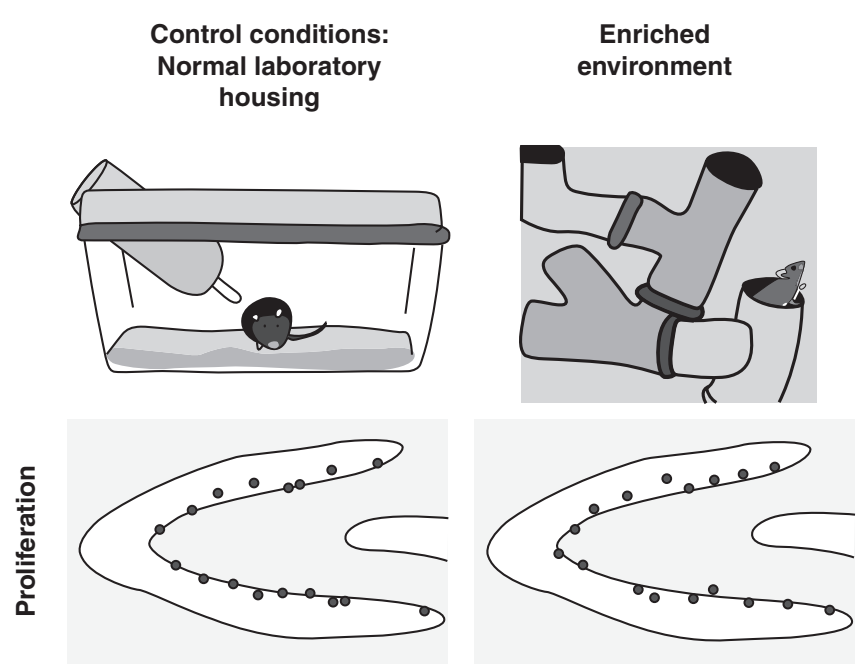

Normal precursor cell proliferation
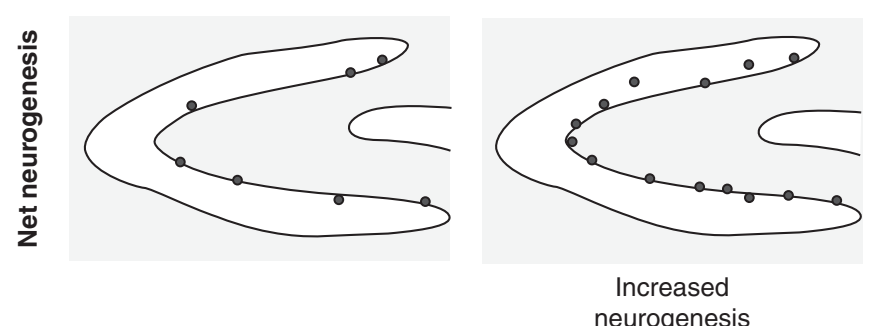
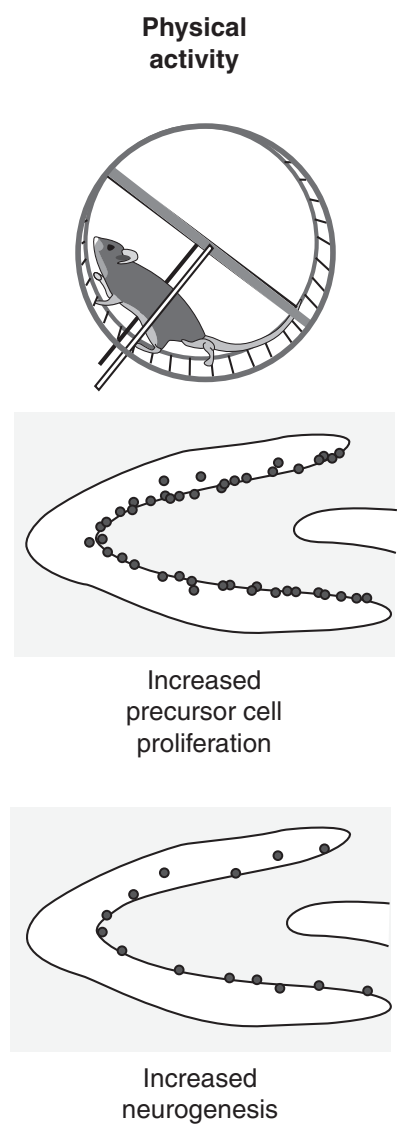

Figure 2. Different types of activity differently affect adult hippocampal neurogenesis. Whereas presumably nonspecific stimuli, such as physical activity, increase the proliferation of precursor cells in the dentate gyrus, presumably more specific stimuli like the exposure to a complex environment (environmental enrichment) preferentially increases the survival of newborn cells (the figure is a schematic rendering of data from Van Praag et al. 1999).

cells that is available for further neuronal maturation and functional integration (Van Praag et al. 1999; Kronenberg et al. 2003). It has sometimes been postulated that the particular type of physical activity might influence the results, because in studies on the effects of water-maze training on neurogenesis, a yoked control that swam for the same time as the groups in the learning test had no signs of increased neurogenesis (Van Praag et al. 1999; Ehninger and Kempermann 2006). However, in those studies, swimming lasted only a few minutes per day; from these data, the conclusion that swimming is less efficient than running is not justified (Ra et al. 2002). Voluntary wheel running and forced exercise in treadmill paradigms thus remain the best-studied paradigms of physical exercise in rodents with respect to their effects on adult neurogenesis (Van Praag et al. 1999; Trejo et al. 2001; Ra et al. 2002; Kronenberg et al. 2003, 2005; Kim et al. 2004; Naylor et al. 2005). The effects of voluntary wheel running on hippocampal neurogenesis were even transmissible from the exercising pregnant mouse to her offspring (BickSander et al. 2006).

The initial stimulus that mediates the effects of running on the precursor cells is not known. After prolonged exercise, a shift in cell-cycle length has been observed (Farioli- 
Vecchioli et al. 2014), which was absent in the very first phase (Fischer et al. 2014).

In contrast, stimuli that supposedly are more specific to hippocampal function have no or a limited effect on cell proliferation but recruit new neurons for long-term survival (Fig. $2)$. This distinction, however, is strain dependent and, thus, presumably again subject to genetic determination (Kempermann et al. 1998a). We have used environmental enrichment to show this survival-promoting effect (Kempermann et al. 1997b, 2002; Kempermann and Gage 1999; Kronenberg et al. 2003); others have shown such results with specific stimuli, such as learning tasks (Gould et al. 1999; Dobrossy et al. 2003; Leuner et al. 2004; Hairston et al. 2005). Also, the induction of long-term potentiation, the putative electrophysiological correlate of learning, increased neurogenesis in the adult hippocampus (Bruel-Jungerman et al. 2006). Olfactory enrichment had analogous effects on precursor cells migrating to the olfactory bulb from the SVZ but no parallel effect in the hippocampus (Rochefort et al. 2002).

The activity-dependent recruitment for long-term survival mostly takes place once the cells have exited from the cell cycle and have made first synaptic contacts (Brandt et al. 2003; Kempermann et al. 2004a; Tashiro et al. 2007). Environmental enrichment during this critical period in the development of a new neuron would provide the appropriate behavioral stimulus for the selective recruitment. In rodents, this time window appears to be relatively narrow and might amount to not more than 2 to 3 wk (Gould et al. 1999; Greenough et al. 1999; Dobrossy et al. 2003; Leuner et al. 2004; Hairston et al. 2005; Ehninger and Kempermann 2006). The steep decline in survival after exit from the cell cycle suggests that most of the recruitment actually occurs very early. This implies that, quantitatively, the activity-dependent selection occurs well before the cells are finally integrated into the existing network. Although dendrites are extended early after exit from the cell cycle (Plumpe et al. 2006), dendritic spines first appear only 2 to 3 wk later (Zhao et al. 2006). It seems that the regulatory synaptic drive that reaches the cells even on a progenitor level is $\gamma$-aminobutyric acid (GABA)ergic and responsible for the subsequent neurodevelopmental events (Tozuka et al. 2005; Wang et al. 2005; Ge et al. 2006). Learning, for example, affects the shape of the dendritic tree that forms during the maturation stage (Tronel et al. 2010).

The effects of exercise and environmental enrichment are additive (Fabel et al. 2009), which indicates that increasing the potential for neurogenesis is sufficient to increase the actual use of the recruitable cells in the case of cognitive stimulation.

From the fact that in the course of their individual development, new neurons in the adult hippocampus go through a phase of increased synaptic sensitivity (and a reduced threshold for the induction of long-term potentiation) (Wang et al. 2000; Schmidt-Hieber et al. 2004; Garthe et al. 2009), it has been inferred that during this particular phase the new cells might also serve a particular function, presumably distinct from their lasting function once they are fully integrated into the network. On the other hand, one might argue that the increased synaptic sensitivity serves the preferential recruitment of the new cells into the existing network rather than a function of its own. The hypothesis is that transient and persistent function are linked and that the former serves the latter (Kempermann et al. 2004b).

In long-term experiments, both environmental enrichment and voluntary wheel running had additional effects that had not been apparent in more acute settings. In both paradigms, survival-promoting effects acted on the precursor cells themselves and not only on their progeny (Kempermann and Gage 1999; Kempermann et al. 2002; Kronenberg et al. 2006). Long-term wheel running had both pro-proliferative and survival-promoting effects, the latter resulting in an increased potential for neurogenesis that went unused in the absence of additional specific (cognitive) stimuli (Kronenberg et al. 2006). Under running there is a lasting switch toward increased differentiation and maturation (Merkley et al. 2014), further suggesting that the exercise stimulus lastingly changes cellular programs. Long-term exercise is effective with respect to morphological indi- 
cators as well as functional readout if applied in the midlife of a mouse (Marlatt et al. 2012). Physical activity remains effective into old age (van Praag et al. 2005).

Similar to voluntary physical exercise, chemically induced seizures as a model of pansynaptic activation led to an increase in cell proliferation in the adult hippocampus (Bengzon et al. 1997; Parent et al. 1997; Parent and Lowenstein 2002). There is also a nonspecific response in cell proliferation in cases of various types of pathology throughout the brain. All of these might lead to an initial increase in net neurogenesis but arguably this increase will not last. Acute effects of nonspecific stimuli "wear off" (Kralic et al. 2005; Kronenberg et al. 2006). From a functional perspective this seems plausible: nonspecific, pro-proliferative stimuli would lead to a transient increase in a potential for new neurons, but additional survival-promoting stimuli, presumably more specific to hippocampal function, would be necessary. Net regulation of adult neurogenesis is, thus, dependent on the activitydependent control of two regulatory stages: expansion and selective survival. Transient expansion of the precursor pool apparently occurs under many circumstances of increased "activity" in a very general sense. Somewhat surprisingly then, it turned out to be sufficient to increase the number of available new neurons by inhibiting their apoptosis to observe a functional benefit (here with respect to "pattern separation") (Sahay et al. 2011).

The fact that nonspecific activity has any lasting effect at all seems surprising (Kempermann et al. 2010). Why should physical activity have any functionally relevant consequences on the hippocampal network? For a rodent, "cognition" is inseparable from locomotion. An animal discovers the world by moving in it. Learning is to a large degree spatial learning and navigation. Only with the development of language did cognition independent of locomotion become possible. If adult neurogenesis thus allows an activity-dependent adaptation of the neuronal network in the hippocampus, locomotor activity would reflect movement in the environment. Increased locomotion might (not alone but prominently) be a sign of in- creased exploration. Increased activity in the sense of locomotion might, thus, generally be indicative of situations of increased likelihood of novel and complex cognitive stimuli. Physical activity would, thus, not by itself provide specific hippocampus-relevant stimuli that induce net neurogenesis but be associated with a greater chance to encounter specific relevant stimuli. Only in the laboratory situation can we separate these two conditions.

Supporting this idea is the observation that, in a large group of mice in an enriched environment, variability in adult hippocampal neurogenesis increased. Levels of adult neurogenesis correlated with a longitudinally acquired behavioral parameter called "roaming entropy," which is a measure of territorial coverage and, hence, a proxy for exploration (Freund et al. 2013).

\section{MECHANISMS OF ACTIVITY-DEPENDENT REGULATION}

Precursor cells in the neurogenic niches of the adult brain might be able to directly sense activity and translate this stimulus into the initiation of a program of neuronal development. Deisseroth and colleagues reported that even short-lasting and mild depolarization of hippocampal precursor cells in vitro caused long-lasting increases in the number of newly generated neurons. In the proliferating cells, a fast up-regulation of NeuroD was found, accompanied by a down-regulation of transcription factors favoring glial development (Deisseroth et al. 2004). The effect was dependent on $N$-methylD-aspartate (NMDA) receptor signaling and mediated by calcium signaling. The potential relevance of NMDA receptors for the control of adult neurogenesis had been noted early (Cameron et al. 1995; Nacher and McEwen 2006) and might provide an interesting conceptual link between synaptic plasticity and adult neurogenesis as an example of cellular plasticity.

Given the possibility that systemic factors might be involved in the activity-dependent control of adult neurogenesis, one has tried early to identify circulating factors that would mediate the up-regulating effects of exercise on neurogenesis. For both insulin-like growth fac- 
tor 1 (IGF-1) and vascular endothelial growth factor (VEGF), the argument has been made that either factor could serve as sole mediator between exercise and neurogenesis (Trejo et al. 2001; Fabel et al. 2003). Blocking IGF-1 or VEGF prevented the exercise-induced increase in adult hippocampal neurogenesis. Because both factors have been implied as important for neurogenesis in general, the interpretation of these results is ambiguous; they rather show that both factors are necessary for the regulation of neurogenesis but do not prove that they are sufficient. In fact, the two claims are mutually exclusive.

Fibroblast growth factor 2 (FGF-2), which is necessary to grow hippocampal precursor cells in vitro (Palmer et al. 1995), is another key candidate for mediating activity-dependent effects across the life span (Jin et al. 2003), because FGF-2 can act systemically (Wagner et al. 1999), is proneurogenic in the adult brain (Kuhn et al. 1997), declines with age (Shetty et al. 2005), is up-regulated in activity paradigms (BickSander et al 2006), and FGF-2 receptor expression is prominent in the neurogenic zones of the adult and aged rodent brain (Chadashvili and Peterson 2006).

The exercise-induced increase in adult neurogenesis was also absent in mice lacking tryptophane hydroxylase 2 and, thus, do not have cerebral serotonin (Klempin et al. 2013) and after inhibition of endocannabinoid signaling (Wolf et al. 2010). The involvement of other neurotransmitter systems seems plausible.

Hormones constitute the key regulatory system that has been investigated as a potential link between age effects on neurogenesis and its activity-dependent regulation. To date, most information is available on the effects of glucocorticoids. Acute stress decreases the proliferation of precursor cells and seems to do so through the action of corticosterone (Mirescu and Gould 2006). Stress elevates glucocorticoid levels and stimulates glutamate release in the hippocampus. This leads to a down-regulation of precursor cell proliferation in the adult dentate gyrus (Gould et al. 1997; Gould and Tanapat 1999). The stress-induced effects of glucocorticoids have been linked to age-related cognitive prob- lems in humans (Heffelfinger and Newcomer 2001; Magri et al. 2006). In animal models, the effects of chronic stress and chronically high levels of corticosterone on adult neurogenesis have been rather difficult to assess, and the data do not yet provide a clear picture. A number of chronic stress models did not show changes in adult neurogenesis (Heine et al. 2004b, 2005). In addition, the activity-based models of increased levels of adult neurogenesis, voluntary wheel running and environmental enrichment, are associated not with lower but with higher serum levels of corticosterone (Van Praag et al. 1999). Nevertheless, adult neurogenesis in tree shrews was more vulnerable to chronic psychosocial stress in old rather than in young animals (Simon et al. 2005).

Age-related cognitive decline as well as the age-dependent decrease in adult neurogenesis might be attributable to chronically increased glucocorticoid levels even in the absence of stressful experience, because a dysregulation of the hypothalamic pituitary adrenal (HPA) system might lead to increased serum corticosterone levels (Koehl et al. 1999; Sapolsky 1999). The age-related reduction in adult neurogenesis might be a result of the increased corticosteroid levels in older age (Cameron and McKay 1999), although some conflicting data exist (Heine et al. 2004a). Corticosteroid receptor expression increases on precursor cells in older age, possibly making them more sensitive to corticosterone action (Garcia et al. 2004). Interestingly, the expression pattern did not change under voluntary wheel running or environmental enrichment. Even a brief treatment with glucocorticoid receptor antagonist mifepristone increased hippocampal neurogenesis and improved cognition in old rats (Mayer et al. 2006). The prevention of glucocorticoid-mediated effects in aging rats maintained higher neurogenesis levels (Cameron and McKay 1999; Montaron et al. 2006). Because both environmental enrichment and physical activity are associated with increased rather than decreased levels of corticosteroids, however, the interaction might be more complex than these data alone suggest. Not unexpectedly, one study found that acute stress, for example, interfered with the up-regulating effect of wheel 
running on adult neurogenesis (Stranahan et al. 2006). Activity-dependent control thus stands in regulatory competition with other factors, not only on the behavioral but also on the mechanistic level.

Sex hormones, both female and male, can influence adult neurogenesis (Galea et al. 2006; Tatar et al. 2013). In the hippocampus of female rodents, cell proliferation peaks during the estrogen-high-proestrous phase (Tanapat et al. 1999). Exogenous application of estradiol led only to a transient increase in cell proliferation, presumably because a compensating feedback mechanism might exist (Ormerod et al. 2003). The different female sex hormones show complex interactions and differential effects (Chan et al. 2014). Estrogen has neuroprotective properties, and estrogen deficiency during menopause can be associated with cognitive dysfunction. Estrogen substitution therapy in postmenopausal women might have a positive effect on these problems, but no consistent link between hormone-replacement therapy and cognitive performance has been found (Hogervorst et al. 2002; Low and Anstey 2006). In songbirds, a fundamental link between testosterone signaling (including via synapses) and the control of adult neurogenesis has been described (Goldman and Nottebohm 1983; Louissaint et al. 2002; Brenowitz 2014).

In mammals, sex hormones presumably play a largely modulatory role on neurogenesis. Estrogen and IGF-1 interact in the promotion of neuronal survival (Garcia-Segura et al. 2000). Furthermore, estrogen might act through a serotonin-mediated pathway to stimulate precursor cell proliferation in the adult dentate gyrus (Banasr et al. 2001). Related to this might be the finding that previous sexual experience was associated with greater levels of adult neurogenesis (and partly cognitive test performance) in rats (Glasper and Gould 2013).

\section{PATHOLOGICAL AGING, NEURODEGENERATION, AND ADULT NEUROGENESIS}

In pathological aging, changes to cognitive functions exceed the level that is considered to be normal, and specific pathological events can be detected. Neurodegenerative disease is defined by an age-dependent progressive loss of neurons owing to the accumulation of misfolded proteins (e.g., $\alpha$ synuclein in Parkinson's disease [PD] or amyloid $\beta$ in Alzheimer's disease $[\mathrm{AD}])$. In a wider sense, neurodegenerative disease includes secondary degeneration, such as in inflammatory disorders or ischemia.

Enthusiasm about adult neurogenesis has led to the speculative idea that neurodegeneration might only represent the flip side of neuronal development and regeneration. Neurodegenerative disorders might be a consequence of a lack of neuroregeneration rather than an increase in degeneration per se. The underlying assumption is that, under normal conditions, degeneration and regeneration and cell death and birth were in equilibrium. Under pathological conditions, this equilibrium might become disturbed and lead to the manifestations of the disease. There is very little evidence that this concept applies in a fundamental sense, although adult neurogenesis responds to a wide range of pathologies, and stem-cell biology has raised new hopes for regenerative medicine with respect to aging-related disorders, because stem cells embody the potential for regeneration, most notably in stroke (Kokaia and Lindvall 2012; Chen et al. 2014). In contrast, it might be the physiological function of the new neurons that is influenced or impaired by aging and that, if adequately preserved, adult neurogenesis might contribute to the compensation of age-dependent functional losses. In the course of neurodegenerative disorders, there is an increase in a specific degenerative pathology, not just a reduction in regeneration.

Despite being exceptional and rare in old age, adult neurogenesis might be of profound functional significance because it occurs at a strategic bottleneck location in the hippocampus (Kempermann 2002). A failure of adult hippocampal neurogenesis might contribute to different types of age-related neurological and psychiatric disorders (Steiner et al. 2006), most notably major depression (Jacobs et al. 2000), neurodegenerative disorders like $\mathrm{AD}$ (Jin et al. 2004), and the cognitive decline 
associated with PD (Hoglinger et al. 2004). In a mouse model of Down syndrome (DS) (Ts65Dn), adult neurogenesis in the olfactory bulb was normal in young mice but decreased with age, presumably through a depletion of the precursor cell population (Bianchi et al. 2014).

Genetically induced neuronal cell loss in the hippocampus, especially CA1, induced neurogenesis in the dentate gyrus. Perhaps not surprisingly in this setup, no functional recovery was observed for the lesion-induced behavioral impairments (Yeung et al. 2014).

Nevertheless, the result is in line with other reports: that damage to the brain can induce adult neurogenesis but that a benefit can only be expected for the contributions the new neurons make to the function of the dentate gyrus.

In addition, adult neurogenesis might represent the tip of the iceberg of a much larger spectrum of cellular plasticity. The recent increase in knowledge about NG2 cells that might turn out to constitute a previously unrecognized entity of cells with precursor cell properties indicates that, in terms of cellular plasticity, the adult brain contains still largely uncharted terrain (Mallon et al. 2002; Nishiyama et al. 2002). The fact that, in the adult brain, cellular regeneration after damage is scarce might have misled us to believe that it was absent in general. There are, thus, aspects of activity-dependent plasticity related to neural precursor cell biology that are independent of neurogenesis in the canonical neurogenic regions of the adult brain.

\section{THE INTERACTION BETWEEN EFFECTS OF AGING AND ACTIVITY ON ADULT NEUROGENESIS: THE NEUROGENIC RESERVE HYPOTHESIS}

The decrease in adult hippocampal neurogenesis over the course of life is paralleled by a loss in certain aspects of cognitive performance (Driscoll et al. 2006; Gil-Mohapel et al. 2013). However, even in old age, enrichment and exercise stimulate adult neurogenesis and test performance. This clearly suggests that the parallel decline is amenable to interventions.
The cognitive or neural reserve theory proposes that neuronal networks that are strengthened by constant cognitive challenges can withstand degeneration and functional loss to a greater extent than less-trained networks (Satz 1993; Stern 2002). Cognitive reserve thus describes the ability of the brain to recruit compensatory neuronal networks in the case of degeneration or age-related loss. The cognitive reserve hypothesis might explain the large interindividual differences in coping with the symptoms of dementia in neurodegenerative diseases and the variable relation between neuropathological findings and clinical manifestation of the disease. Cellular plasticity and adult neurogenesis might contribute to these effects. In fact, the neural reserve might (among other aspects) represent the interaction between age effects and activity effects in the control of neurogenesis.

The neural reserve hypothesis can be tested in the animal model of environmental enrichment. Environmental enrichment leads to an increase in adult hippocampal neurogenesis, and this effect is seen even in old animals where the baseline level of adult neurogenesis is very low (Kempermann et al. 1998b). Long-term environmental enrichment for the second half of the life of a mouse led to a sustained induction of adult neurogenesis (in contrast to effects that might be seen only after acute exposure), suggesting that living in a challenging environment has lasting consequences on the potential for cellular hippocampal plasticity (Kempermann et al. 2002).

In line with the results discussed in the previous paragraphs, adult hippocampal neurogenesis might, thus, contribute to a structural or neural reserve that if appropriately trained early in life might provide a compensatory buffer of brain plasticity in the face of increasing neurodegeneration or nonpathological age-related functional losses.

Environmental enrichment, for example, had positive effects on symptoms and the cause of disease in murine models of AD (Arendash et al. 2004; Wolf et al. 2006). Despite stable A $\beta$ plaque load enrichment improved learning and memory performance in aged amyloid precursor protein (APP) transgenic mice. The effect 
was not apparent in APP transgenic mice with access to a running wheel. The enhancement of cognitive function was paralleled by a hippocampal-specific increase of neurotrophic factors and increased neurogenesis (Wolf et al. 2006).

Despite such suggestive findings, there is still only limited information on the activitydependent parameters that help to prevent the age-dependent decrease in adult neurogenesis and maintain cellular plasticity. A number of more or less "usual suspects," such as corticosterone (Cameron and McKay 1999; Montaron et al. 2006), IGF-1 (Lichtenwalner et al. 2001), vitamin A (Touyarot et al. 2013), melatonin (Ramirez-Rodriguez et al. 2012), and also exercise (Kronenberg et al. 2006) and enrichment (Kempermann et al. 2002), dominate the discussion, but as yet relatively little is known about the intracellular signaling pathways that mediate, modulate, and coordinate those effects. Blood-borne factors from young mice were able to rejuvenate the neurogenic niche in older mice and, among these, GDF11 was sufficient to elicit such response (Katsimpardi et al. 2014).

A common downstream pathway might be brain-derived neurotrophic factor (BDNF) signaling (Marlatt et al. 2012; Hsiao et al. 2014), but for the specificity of this assumption see the discussion above. BDNF signals through the cAMP-response element-binding protein (CREB), which is a key factor controlling neuronal survival, learning, and memory, and of plasticity in the nervous system. Fittingly, the hippocampal expression of CREB decreases with age (Kudo et al. 2005). CREB is expressed by PSA-NCAM-positive progenitor cells and their postmitotic progeny in the adult hippocampus (Nakagawa et al. 2002a) and the activation of CREB increases many aspects of adult neurogenesis, including proliferation, survival, and dendritic maturation (Nakagawa et al. 2002b; Fujioka et al. 2004). However, intracellular signaling from numerous pathways converges on CREB, so that CREB action can only be understood in the context of larger networks of regulatory mechanisms. In a related context, a comprehensive model of transcriptional mechanisms that distinguish successful from unsuccessful aging in the hippocampus has been proposed (Lund et al. 2004; Pawlowski et al. 2009) but remains to be applied to adult neurogenesis.

\section{REFERENCES}

${ }^{*}$ Reference is also in this collection.

Altman J, Das GD. 1965. Autoradiographic and histological evidence of postnatal hippocampal neurogenesis in rats. J Comp Neurol 124: 319-335.

Arendash GW, Garcia MF, Costa DA, Cracchiolo JR, Wefes IM, Potter H. 2004. Environmental enrichment improves cognition in aged Alzheimer's transgenic mice despite stable $\beta$-amyloid deposition. Neuroreport 15: 17511754.

Banasr M, Hery M, Brezun JM, Daszuta A. 2001. Serotonin mediates oestrogen stimulation of cell proliferation in the adult dentate gyrus. Eur J Neurosci 14: 1417-1424.

Barker JM, Wojtowicz JM, Boonstra R. 2005. Where's my dinner? Adult neurogenesis in free-living food-storing rodents. Genes Brain Behav 4: 89-98.

Ben Abdallah N, Slomianka L, Vyssotski AL, Lipp HP. 2010. Early age-related changes in adult hippocampal neurogenesis in C57 mice. Neurobiol Aging 31: 151-161.

Bengzon J, Kokaia Z, Elmér E, Nanobashvili A, Kokaia M, Lindvall O. 1997. Apoptosis and proliferation of dentate gyrus neurons after single and intermittent limbic seizures. Proc Natl Acad Sci 94: 10432-10437.

* Bergmann O, Spalding KL, Frisén J. 2015. Adult neurogenesis in humans. Cold Spring Harb Perspect Biol 7: a18994.

Bianchi P, Bettini S, Guidi S, Ciani E, Trazzi S, Stagni F, Ragazzi E, Franceschini V, Bartesaghi R. 2014. Age-related impairment of olfactory bulb neurogenesis in the Ts65Dn mouse model of Down syndrome. Exp Neurol 251: $1-11$.

Bick-Sander A, Steiner B, Wolf SA, Babu H, Kempermann G. 2006. Running in pregnancy transiently increases postnatal hippocampal neurogenesis in the offspring. Proc Natl Acad Sci 103: 3852-3857.

Brandt MD, Jessberger S, Steiner B, Kronenberg G, Reuter K, Bick-Sander A, von der Behrens W, Kempermann G. 2003. Transient calretinin expression defines early postmitotic step of neuronal differentiation in adult hippocampal neurogenesis of mice. Mol Cell Neurosci 24: 603613.

Brann JH, Firestein SJ. 2014. A lifetime of neurogenesis in the olfactory system. Front Neurosci 8: 182.

Brenowitz EA. 2014. Transsynaptic trophic effects of steroid hormones in an avian model of adult brain plasticity. Front Neuroendocrinol 37: 119-128.

Brown J, Cooper-Kuhn CM, Kempermann G, Van Praag H, Winkler J, Gage FH, Kuhn HG. 2003. Enriched environment and physical activity stimulate hippocampal but not olfactory bulb neurogenesis. Eur J Neurosci 17: 2042-2046.

Bruel-Jungerman E, Davis S, Rampon C, Laroche S. 2006. Long-term potentiation enhances neurogenesis in the adult dentate gyrus. J Neurosci 26: 5888-5893. 
Buckwalter MS, Yamane M, Coleman BS, Ormerod BK, Chin JT, Palmer T, Wyss-Coray T. 2006. Chronically increased transforming growth factor- $\beta 1$ strongly inhibits hippocampal neurogenesis in aged mice. Am J Pathol 169: 154-164.

Cameron HA, McKay RD. 1999. Restoring production of hippocampal neurons in old age. Nat Neurosci 2: 894897.

Cameron HA, McEwen BS, Gould E. 1995. Regulation of adult neurogenesis by excitatory input and NMDA receptor activation in the dentate gyrus. J Neurosci 15: 46874692.

Cameron HA, Hazel TG, McKay RD. 1998. Regulation of neurogenesis by growth factors and neurotransmitters. $J$ Neurobiol 36: 287-306.

Caporaso GL, Lim DA, Alvarez-Buylla A, Chao MV. 2003. Telomerase activity in the subventricular zone of adult mice. Mol Cell Neurosci 23: 693-702.

Chadashvili T, Peterson DA. 2006. Cytoarchitecture of fibroblast growth factor receptor 2 (FGFR-2) immunoreactivity in astrocytes of neurogenic and non-neurogenic regions of the young adult and aged rat brain. J Comp Neurol 498: 1-15.

Chan M, Chow C, Hamson DK, Lieblich SE, Galea LA. 2014. Effects of chronic oestradiol, progesterone and medroxyprogesterone acetate on hippocampal neurogenesis and adrenal mass in adult female rats. J Neuroendocrinol 26: 386-399.

Chen J, Venkat P, Zacharek A, Chopp M. 2014. Neurorestorative therapy for stroke. Front Hum Neurosci 8: 382.

Deisseroth K, Singla S, Toda H, Monje M, Palmer TD, Malenka RC. 2004. Excitation-neurogenesis coupling in adult neural stem/progenitor cells. Neuron 42: 535-552.

Dobrossy MD, Drapeau E, Aurousseau C, Le Moal M, Piazza PV, Abrous DN. 2003. Differential effects of learning on neurogenesis: Learning increases or decreases the number of newly born cells depending on their birth date. $\mathrm{Mol}$ Psychiatry 8: 974-982.

Doetsch F, Garcia-Verdugo JM, Alvarez-Buylla A. 1997. Cellular composition and three-dimensional organization of the subventricular germinal zone in the adult mammalian brain. J Neurosci 17: 5046-5061.

Driscoll I, Howard SR, Stone JC, Monfils MH, Tomanek B, Brooks WM, Sutherland RJ. 2006. The aging hippocampus: A multi-level analysis in the rat. Neuroscience 139: $1173-1185$.

Ehninger D, Kempermann G. 2003. Regional effects of wheel running and environmental enrichment on cell genesis and microglia proliferation in the adult murine neocortex. Cereb Cortex 13: 845-851.

Ehninger D, Kempermann G. 2006. Paradoxical effects of learning the Morris water maze on adult hippocampal neurogenesis in mice may be explained by a combination of stress and physical activity. Genes Brain Behav 5: 29-39.

Encinas JM, Michurina TV, Peunova N, Park JH, Tordo J, Peterson DA, Fishell G, Koulakov A, Enikolopov G. 2011. Division-coupled astrocytic differentiation and age-related depletion of neural stem cells in the adult hippocampus. Cell Stem Cell 8: 566-579.
Enwere E, Shingo T, Gregg C, Fujikawa H, Ohta S, Weiss S. 2004. Aging results in reduced epidermal growth factor receptor signaling, diminished olfactory neurogenesis, and deficits in fine olfactory discrimination. J Neurosci 24: 8354-8365.

Eriksson PS, Perfilieva E, Bjork-Eriksson T, Alborn AM, Nordborg C, Peterson DA, Gage FH. 1998. Neurogenesis in the adult human hippocampus. Nat Med 4: 13131317.

Fabel K, Fabel K, Tam B, Kaufer D, Baiker A, Simmons N, Kuo CJ, Palmer TD. 2003. VEGF is necessary for exerciseinduced adult hippocampal neurogenesis. Eur J Neurosci 18: $2803-2812$.

Fabel K, Wolf SA, Ehninger D, Babu H, Galicia PL, Kempermann G. 2009. Additive effects of physical exercise and environmental enrichment on adult hippocampal neurogenesis in mice. Front Neurosci 3: 50.

Farioli-Vecchioli S, Mattera A, Micheli L, Ceccarelli M, Leonardi L, Saraulli D, Costanzi M, Cestari V, Rouault JP, Tirone F. 2014. Running rescues defective adult neurogenesis by shortening the length of the cell cycle of neura stem and progenitor cells. Stem Cells 32: 1968-1982.

Fischer TJ, Walker TL, Overall RW, Brandt MD, Kempermann G. 2014. Acute effects of wheel running on adult hippocampal precursor cells in mice are not caused by changes in cell cycle length or S phase length. Front Neurosci 8: 314.

Freund J, Brandmaier AM, Lewejohann L, Kirste I, Kritzler M, Krüger A, Sachser N, Lindenberger U, Kempermann G. 2013. Emergence of individuality in genetically identical mice. Science 340: 756-759.

Fujioka T, Fujioka A, Duman RS. 2004. Activation of cAMP signaling facilitates the morphological maturation of newborn neurons in adult hippocampus. J Neurosci 24: 319-328.

Galea LA, Spritzer MD, Barker JM, Pawluski JL. 2006. Gonadal hormone modulation of hippocampal neurogenesis in the adult. Hippocampus 16: 225-232.

Garcia A, Steiner B, Kronenberg G, Bick-Sander A, Kempermann G. 2004. Age-dependent expression of glucocorticoid- and mineralocorticoid receptors on neural precursor cell populations in the adult murine hippocampus. Aging Cell 3: 363-371.

Garcia-Segura LM, Cardona-Gomez GP, Chowen JA, Azcoitia I. 2000. Insulin-like growth factor-I receptors and estrogen receptors interact in the promotion of neuronal survival and neuroprotection. J Neurocytol 29: 425-437.

Garthe A, Behr J, Kempermann G. 2009. Adult-generated hippocampal neurons allow the flexible use of spatially precise learning strategies. PLoS ONE 4: e5464.

Ge S, Goh EL, Sailor KA, Kitabatake Y, Ming GL, Song H. 2006. GABA regulates synaptic integration of newly generated neurons in the adult brain. Nature 439: 589-593.

Gebara E, Sultan S, Kocher-Braissant J, Toni N. 2013. Adult hippocampal neurogenesis inversely correlates with microglia in conditions of voluntary running and aging. Front Neurosci 7: 145.

Gil-Mohapel J, Brocardo PS, Choquette W, Gothard R, Simpson JM, Christie BR. 2013. Hippocampal neurogenesis levels predict WATERMAZE search strategies in the aging brain. PLoS ONE 8: e75125. 
G. Kempermann

Glasper ER, Gould E. 2013. Sexual experience restores agerelated decline in adult neurogenesis and hippocampal function. Hippocampus 23: 303-312.

Goldman SA, Nottebohm F. 1983. Neuronal production, migration and differentiation in a vocal control nucleus of the adult female canary brain. Proc Acad Sci 80: 23902394.

Goritz C, Frisen J. 2012. Neural stem cells and neurogenesis in the adult. Cell Stem Cell 10: 657-659.

Gould E, Tanapat P. 1999. Stress and hippocampal neurogenesis. Biol Psychiatry 46: 1472-1479.

Gould E, McEwen BS, Tanapat P, Galea LA, Fuchs E. 1997. Neurogenesis in the dentate gyrus of the adult tree shrew is regulated by psychosocial stress and NMDA receptor activation. J Neurosci 17: 2492-2498.

Gould E, Beylin A, Tanapat P, Reeves A, Shors TJ. 1999. Learning enhances adult neurogenesis in the hippocampal formation. Nat Neurosci 2: 260-265.

Greenough WT, Cohen NJ, Juraska JM. 1999. New neurons in old brains: Learning to survive? Nat Neurosci 2: 203205.

Hairston IS, Little MT, Scanlon MD, Barakat MT, Palmer TD, Sapolsky RM, Heller HC. 2005. Sleep restriction suppresses neurogenesis induced by hippocampus-dependent learning. J Neurophysiol 94: 4224-4233.

Hattiangady B, Shetty AK. 2008. Aging does not alter the number or phenotype of putative stem/progenitor cells in the neurogenic region of the hippocampus. Neurobiol Aging 29: 129-147.

Hattiangady B, Rao MS, Shetty GA, Shetty AK. 2005. Brainderived neurotrophic factor, phosphorylated cyclic AMP response element binding protein and neuropeptide $\mathrm{Y}$ decline as early as middle age in the dentate gyrus and CA1 and CA3 subfields of the hippocampus. Exp Neurol 195: $353-371$.

Heffelfinger AK, Newcomer JW. 2001. Glucocorticoid effects on memory function over the human life span. Dev Psychopathol 13: 491-513.

Heine VM, Maslam S, Joels M, Lucassen PJ. 2004a. Prominent decline of newborn cell proliferation, differentiation, and apoptosis in the aging dentate gyrus, in absence of an age-related hypothalamus-pituitary-adrenal axis activation. Neurobiol Aging 25: 361-375.

Heine VM, Maslam S, Zareno J, Joels M, Lucassen PJ. 2004b. Suppressed proliferation and apoptotic changes in the rat dentate gyrus after acute and chronic stress are reversible. Eur J Neurosci 19: 131-144.

Heine VM, Zareno J, Maslam S, Joels M, Lucassen PJ. 2005 Chronic stress in the adult dentate gyrus reduces cell proliferation near the vasculature and VEGF and Flk-1 protein expression. Eur J Neurosci 21: 1304-1314.

Hogervorst E, Yaffe K, Richards M, Huppert F. 2002. Hormone replacement therapy for cognitive function in postmenopausal women. Cochrane Database Syst Rev CD003122.

Hoglinger GU, Rizk P, Muriel MP, Duyckaerts C, Oertel WH, Caille I, Hirsch EC. 2004. Dopamine depletion impairs precursor cell proliferation in Parkinson disease. Nat Neurosci 7: 726-735.

Hsiao YH, Hung HC, Chen SH, Gean PW. 2014. Social interaction rescues memory deficit in an animal model of Alzheimer's disease by increasing BDNF-dependent hippocampal neurogenesis. J Neurosci 34: 16207-16219.

Jacobs BL, Praag H, Gage FH. 2000. Adult brain neurogenesis and psychiatry: A novel theory of depression. Mol Psychiatry 5: 262-269.

Jin K, Sun Y, Xie L, Batteur S, Mao XO, Smelick C, Logvinova A, Greenberg DA. 2003. Neurogenesis and aging: FGF-2 and HB-EGF restore neurogenesis in hippocampus and subventricular zone of aged mice. Aging Cell 2: 175- 183 .

Jin K, Galvan V, Xie L, Mao XO, Gorostiza OF, Bredesen DE, Greenberg DA. 2004. Enhanced neurogenesis in Alzheimer's disease transgenic (PDGF-APP ${ }_{\text {Sw,Ind }}$ ) mice. Proc Natl Acad Sci 101: 13363-13367.

* Kang E, Wen Z, Song H, Christian KM, Ming G-1. 2015. Adult neurogenesis and psychiatric disorders. Cold Spring Harb Perspect Biol doi: 10.1101/cshperspect .a19026.

Kaplan MS. 1985. Formation and turnover of neurons in young and senescent animals: An electronmicroscopic and morphometric analysis. Ann NY Acad Sci 457: $173-192$.

Kaplan MS, Bell DH. 1984. Mitotic neuroblasts in the 9-dayold and 11-month-old rodent hippocampus. J Neurosci 4: 1429-1441.

Katsimpardi L, Litterman NK, Schein PA, Miller CM, Loffredo FS, Wojtkiewicz GR, Chen JW, Lee RT, Wagers AJ, Rubin LL. 2014. Vascular and neurogenic rejuvenation of the aging mouse brain by young systemic factors. Science 344: $630-634$.

Kempermann G. 2002. Why new neurons? Possible functions for adult hippocampal neurogenesis. J Neurosci 22: $635-638$.

Kempermann G. 2011. Seven principles in the regulation of adult neurogenesis. Eur J Neurosci 33: 1018-1024.

Kempermann G, Gage FH. 1999. Experience-dependent regulation of adult hippocampal neurogenesis: Effects of long-term stimulation and stimulus withdrawal. Hippocampus 9: 321-332.

Kempermann G, Kuhn HG, Gage FH. 1997a. Genetic influence on neurogenesis in the dentate gyrus of adult mice. Proc Natl Acad Sci 94: 10409-10414.

Kempermann G, Kuhn HG, Gage FH. 1997b. More hippocampal neurons in adult mice living in an enriched environment. Nature 386: 493-495.

Kempermann G, Brandon EP, Gage FH. 1998a. Environmental stimulation of $129 / \mathrm{SvJ}$ mice causes increased cell proliferation and neurogenesis in the adult dentate gyrus. Curr Biol 8: 939-942.

Kempermann G, Kuhn HG, Gage FH. 1998b. Experienceinduced neurogenesis in the senescent dentate gyrus. $J$ Neurosci 18: 3206-3212.

Kempermann G, Gast D, Gage FH. 2002. Neuroplasticity in old age: Sustained fivefold induction of hippocampal neurogenesis by long-term environmental enrichment. Ann Neurol 52: 135-143.

Kempermann G, Gast D, Kronenberg G, Yamaguchi M, Gage FH. 2003. Early determination and long-term persistence of adult-generated new neurons in the hippocampus of mice. Development 130: 391-399. 
Kempermann G, Jessberger S, Steiner B, Kronenberg G. 2004a. Milestones of neuronal development in the adult hippocampus. Trends Neurosci 27: 447-452.

Kempermann G, Wiskott L, Gage FH. 2004b. Functional significance of adult neurogenesis. Curr Opin Neurobiol 14: $186-191$

Kempermann G, Chesler EJ, Lu L, Williams RW, Gage FH. 2006. Natural variation and genetic covariance in adult hippocampal neurogenesis. Proc Natl Acad Sci 103: 780785.

Kempermann G, Fabel K, Ehninger D, Babu H, Leal-Galicia P, Garthe A, Wolf SA. 2010. Why and how physical activity promotes experience-induced brain plasticity. Front Neurosci 4: 189.

Kim YP, Kim H, Shin MS, Chang HK, Jang MH, Shin MC, Lee SJ, Lee HH, Yoon JH, Jeong IG, et al. 2004. Agedependence of the effect of treadmill exercise on cell proliferation in the dentate gyrus of rats. Neurosci Lett 355: $152-154$.

Klempin F, Beis D, Mosienko V, Kempermann G, Bader M, Alenina N. 2013. Serotonin is required for exercise-induced adult hippocampal neurogenesis. J Neurosci 33: 8270-8275.

Koehl M, Darnaudery M, Dulluc J, Van Reeth O, Le Moal M, Maccari S. 1999. Prenatal stress alters circadian activity of hypothalamo-pituitary-adrenal axis and hippocampal corticosteroid receptors in adult rats of both gender. $J$ Neurobiol 40: 302-315.

Kohman RA, Bhattacharya TK, Kilby C, Bucko P, Rhodes JS, 2013. Effects of minocycline on spatial learning, hippocampal neurogenesis and microglia in aged and adult mice. Behav Brain Res 242: 17-24.

Kokaia Z, Lindvall O. 2012. Stem cell repair of striatal ischemia. Prog Brain Res 201: 35-53.

Kralic JE, Ledergerber DA, Fritschy JM. 2005. Disruption of the neurogenic potential of the dentate gyrus in a mouse model of temporal lobe epilepsy with focal seizures. Eur J Neurosci 22: 1916-1927.

Kronenberg G, Reuter K, Steiner B, Brandt MD, Jessberger S, Yamaguchi M, Kempermann G. 2003. Subpopulations of proliferating cells of the adult hippocampus respond differently to physiologic neurogenic stimuli. J Comp Neurol 467: 455-463.

Kronenberg G, Wang LP, Synowitz M, Gertz K, Katchanov J, Glass R, Harms C, Kempermann G, Kettenmann H, Endres M. 2005. Nestin-expressing cells divide and adopt a complex electrophysiologic phenotype after transient brain ischemia. J Cereb Blood Flow Metab 25: 1613-1624.

Kronenberg G, Bick-Sander A, Bunk E, Wolf C, Ehninger D, Kempermann G. 2006. Physical exercise prevents age-related decline in precursor cell activity in the mouse dentate gyrus. Neurobiol Aging 27: 1505-1513.

Kudo K, Wati H, Qiao C, Arita J, Kanba S. 2005. Age-related disturbance of memory and CREB phosphorylation in CA1 area of hippocampus of rats. Brain Res 1054: 30-37.

Kuhn HG, Dickinson-Anson H, Gage FH. 1996. Neurogenesis in the dentate gyrus of the adult rat: Age-related decrease of neuronal progenitor proliferation. J Neurosci 16: 2027-2033.

Kuhn HG, Winkler J, Kempermann G, Thal LJ, Gage FH. 1997. Epidermal growth factor and fibroblast growth fac- tor-2 have different effects on neural progenitors in the adult rat brain. J Neurosci 17: 5820-5829.

Kuipers SD, Schroeder JE, Trentani A. 2014. Changes in hippocampal neurogenesis throughout early development. Neurobiol Aging 36: 365-379.

Kwon YK. 2002. Effect of neurotrophic factors on neuronal stem cell death. J Biochem Mol Biol 35: 87-93.

Lee HW, Blasco MA, Gottlieb GJ, Horner JW II, Greider CW, DePinho RA. 1998. Essential role of mouse telomerase in highly proliferative organs. Nature 392: 569-574.

Leuner B, Mendolia-Loffredo S, Kozorovitskiy Y, Samburg D, Gould E, Shors TJ. 2004. Learning enhances the survival of new neurons beyond the time when the hippocampus is required for memory. J Neurosci 24: $7477-$ 7481.

Lichtenwalner RJ, Forbes ME, Bennett SA, Lynch CD, Sonntag WE, Riddle DR. 2001. Intracerebroventricular infusion of insulin-like growth factor-I ameliorates the age-related decline in hippocampal neurogenesis. Neuroscience 107: 603-613.

Louissaint A Jr, Rao S, Leventhal C, Goldman SA. 2002. Coordinated interaction of neurogenesis and angiogenesis in the adult songbird brain. Neuron 34: 945-960.

Low LF, Anstey KJ. 2006. Hormone replacement therapy and cognitive performance in postmenopausal women-A review by cognitive domain. Neurosci Biobehav Rev 30: 66-84.

Lund PK, Hoyt EC, Bizon J, Smith DR, Haberman R, Helm K, Gallagher M. 2004. Transcriptional mechanisms of hippocampal aging. Exp Gerontol 39: 1613-1622.

Luo J, Daniels SB, Lennington JB, Notti RQ, Conover JC. 2006. The aging neurogenic subventricular zone. Aging Cell 5: 139-152.

Magri F, Cravello L, Barili L, Sarra S, Cinchetti W, Salmoiraghi F, Micale G, Ferrari E. 2006. Stress and dementia: The role of the hypothalamic-pituitary-adrenal axis. Aging Clin Exp Res 18: 167-170.

Mallon BS, Shick HE, Kidd GJ, Macklin WB. 2002. Proteolipid promoter activity distinguishes two populations of NG2-positive cells throughout neonatal cortical development. J Neurosci 22: 876-885.

Marlatt MW, Potter MC, Lucassen PJ, van Praag H. 2012. Running throughout middle-age improves memory function, hippocampal neurogenesis, and BDNF levels in female C57BL/6J mice. Dev Neurobiol 72: 943-952.

Maslov AY, Barone TA, Plunkett RJ, Pruitt SC. 2004. Neural stem cell detection, characterization, and age-related changes in the subventricular zone of mice. J Neurosci 24: $1726-1733$.

Mayer JL, Klumpers L, Maslam S, de Kloet ER, Joels M, Lucassen PJ. 2006. Brief treatment with the glucocorticoid receptor antagonist mifepristone normalises the corticosterone-induced reduction of adult hippocampal neurogenesis. J Neuroendocrinol 18: 629-631.

Mendelsohn AR, Larrick JW. 2011. Overcoming the aging systemic milieu to restore neural stem cell function. Rejuvenation Res 14: 681-684.

Mercier F, Kitasako JT, Hatton GI. 2002. Anatomy of the brain neurogenic zones revisited: Fractones and the fibroblast/macrophage network. J Comp Neurol 451: 170188. 
Merkley CM, Jian C, Mosa A, Tan YF, Wojtowicz JM. 2014 Homeostatic regulation of adult hippocampal neurogenesis in aging rats: Long-term effects of early exercise. Front Neurosci 8: 174.

Miranda CJ, Braun L, Jiang Y, Hester ME, Zhang L, Riolo M, Wang H, Rao M, Altura RA, Kaspar BK, et al. 2012. Aging brain microenvironment decreases hippocampal neurogenesis through Wnt-mediated survivin signaling. Aging Cell 11: 542-552.

Mirescu C, Gould E. 2006. Stress and adult neurogenesis. Hippocampus 16: 233-238.

Molofsky AV, Slutsky SG, Joseph NM, He S, Pardal R, Krishnamurthy J, Sharpless NE, Morrison SJ. 2006. Increasing p16INK4a expression decreases forebrain progenitors and neurogenesis during ageing. Nature 443: 448-452.

Monje ML, Toda H, Palmer TD. 2003. Inflammatory blockade restores adult hippocampal neurogenesis. Science 302: 1760-1765.

Montaron MF, Drapeau E, Dupret D, Kitchener P, Aurousseau C, Le Moal M, Piazza PV, Abrous DN. 2006. Lifelong corticosterone level determines age-related decline in neurogenesis and memory. Neurobiol Aging 27: 645-654.

Nacher J, McEwen BS. 2006. The role of N-methyl-D-asparate receptors in neurogenesis. Hippocampus 16: 267270.

Nakagawa S, Kim JE, Lee R, Chen J, Fujioka T, Malberg J, Tsuji S, Duman RS. 2002a. Localization of phosphorylated cAMP response element-binding protein in immature neurons of adult hippocampus. J Neurosci 22: $9868-$ 9876.

Nakagawa S, Kim JE, Lee R, Malberg JE, Chen J, Steffen C, Zhang YJ, Nestler EJ, Duman RS. 2002b. Regulation of neurogenesis in adult mouse hippocampus by cAMP and the cAMP response element-binding protein. J Neurosci 22: $3673-3682$.

Naylor AS, Persson AI, Eriksson PS, Jonsdottir IH, Thorlin T. 2005. Extended voluntary running inhibits exerciseinduced adult hippocampal progenitor proliferation in the spontaneously hypertensive rat. J Neurophysiol 93: 2406-2414.

Ninkovic J, Mori T, Gotz M. 2007. Distinct modes of neuron addition in adult mouse neurogenesis. J Neurosci 27: 10906-11091.

Nishiyama A, Watanabe M, Yang Z, Bu J. 2002. Identity, distribution, and development of polydendrocytes: NG2-expressing glial cells. J Neurocytol 31: 437-455.

Ormerod BK, Lee TT, Galea LA. 2003. Estradiol initially enhances but subsequently suppresses (via adrenal steroids) granule cell proliferation in the dentate gyrus of adult female rats. J Neurobiol 55: 247-260.

Palmer TD, Ray J, Gage FH. 1995. FGF-2-responsive neuronal progenitors reside in proliferative and quiescent regions of the adult rodent brain. Mol Cell Neurosci 6: 474-486.

Palmer TD, Willhoite AR, Gage FH. 2000. Vascular niche for adult hippocampal neurogenesis. J Comp Neurol 425: 479-494.

Parent JM, Lowenstein DH. 2002. Seizure-induced neurogenesis: Are more new neurons good for an adult brain? Prog Brain Res 135: 121-131.
Parent JM, Yu TW, Leibowitz RT, Geschwind DH, Sloviter RS, Lowenstein DH. 1997. Dentate granule cell neurogenesis is increased by seizures and contributes to aberrant network reorganization in the adult rat hippocampus. J Neurosci 17: 3727-3738.

Pawlowski TL, Bellush LL, Wright AW, Walker JP, Colvin RA, Huentelman MJ. 2009. Hippocampal gene expression changes during age-related cognitive decline. Brain Res 1256: $101-110$.

Plumpe T, Ehninger D, Steiner B, Klempin F, Jessberger S, Brandt M, Römer B, Rodriguez GR, Kronenberg G, Kempermann G. 2006. Variability of doublecortin-associated dendrite maturation in adult hippocampal neurogenesis is independent of the regulation of precursor cell proliferation. BMC Neurosci 7: 77.

Ra SM, Kim H, Jang MH, Shin MC, Lee TH, Lim BV, Kim CJ, Kim EH, Kim KM, Kim SS. 2002. Treadmill running and swimming increase cell proliferation in the hippocampal dentate gyrus of rats. Neurosci Lett 333: 123-126.

Ramirez-Rodriguez G, Vega-Rivera NM, Benitez-King G, Castro-Garcia M, Ortiz-Lopez L. 2012. Melatonin supplementation delays the decline of adult hippocampal neurogenesis during normal aging of mice. Neurosci Lett 530: 53-58.

Rochefort C, Gheusi G, Vincent JD, Lledo PM. 2002. Enriched odor exposure increases the number of newborn neurons in the adult olfactory bulb and improves odor memory. J Neurosci 22: 2679-2689.

Sahay A, Scobie KN, Hill AS, O'Carroll CM, Kheirbek MA, Burghardt NS, Fenton AA, Dranovsky A, Hen R. 2011 Increasing adult hippocampal neurogenesis is sufficient to improve pattern separation. Nature 472: 466-470.

Sapolsky RM. 1999. Glucocorticoids, stress, and their adverse neurological effects: Relevance to aging. Exp Gerontol 34: 721-732.

Satz P. 1993. Brain reserve capacity on symptom onset after brain injury: A formulation and review of evidence for threshold theory. Neuropsychology 7: 273-295.

Schmidt-Hieber C, Jonas P, Bischofberger J. 2004. Enhanced synaptic plasticity in newly generated granule cells of the adult hippocampus. Nature 429: 184-187.

Seaberg RM, van der Kooy D. 2002. Adult rodent neurogenic regions: The ventricular subependyma contains neural stem cells, but the dentate gyrus contains restricted progenitors. J Neurosci 22: 1784-1793.

Seib DR, Corsini NS, Ellwanger K, Plaas C, Mateos A, Pitzer C, Niehrs C, Celikel T, Martin-Villalba A. 2013. Loss of Dickkopf-1 restores neurogenesis in old age and counteracts cognitive decline. Cell Stem Cell 12: 204-214.

Seki T. 2002. Expression patterns of immature neuronal markers PSA-NCAM, CRMP-4 and NeuroD in the hippocampus of young adult and aged rodents. J Neurosci Res 70: 327-334.

Seki T. 2003. Microenvironmental elements supporting adult hippocampal neurogenesis. Anat Sci Int 78: 69-78.

Seki T, Arai Y. 1995. Age-related production of new granule cells in the adult dentate gyrus. Neuroreport 6: 24792482.

Shetty AK, Hattiangady B, Shetty GA. 2005. Stem/progenitor cell proliferation factors FGF-2, IGF-1, and VEGF 
exhibit early decline during the course of aging in the hippocampus: Role of astrocytes. Glia 51: 173-186.

Silva-Vargas V, Crouch EE, Doetsch F. 2013. Adult neural stem cells and their niche: A dynamic duo during homeostasis, regeneration, and aging. Curr Opin Neurobiol 23: 935-942.

Simon M, Czeh B, Fuchs E. 2005. Age-dependent susceptibility of adult hippocampal cell proliferation to chronic psychosocial stress. Brain Res 1049: 244-248.

Spalding KL, Bergmann O, Alkass K, Bernard S, Salehpour M, Huttner HB, Boström E, Westerlund I, Vial C, Buchholz BA, et al. 2013. Dynamics of hippocampal neurogenesis in adult humans. Cell 153: 1219-1227.

Steiner B, Wolf S, Kempermann G. 2006. Adult neurogenesis and neurodegenerative disease. Regen Med 1: 15-28.

Stern Y. 2002. What is cognitive reserve? Theory and research application of the reserve concept. J Int Neuropsychol Soc 8: $448-460$.

Stranahan AM, Khalil D, Gould E. 2006. Social isolation delays the positive effects of running on adult neurogenesis. Nat Neurosci 9: 526-533.

Su P, Zhang J, Zhao F, Aschner M, Chen J, Luo W. 2014. The interaction between microglia and neural stem/precursor cells. Brain Res Bull 109C: 32-38.

Sun LY, Evans MS, Hsieh J, Panici J, Bartke A. 2005. Increased neurogenesis in dentate gyrus of long-lived Ames dwarf mice. Endocrinology 146: 1138-1144.

Tanapat P, Hastings NB, Reeves AJ, Gould E. 1999. Estrogen stimulates a transient increase in the number of new neurons in the dentate gyrus of the adult female rat. J Neurosci 19: 5792-5801.

Tashiro A, Makino H, Gage FH. 2007. Experience-specific functional modification of the dentate gyrus through adult neurogenesis: A critical period during an immature stage. J Neurosci 27: 3252-3259.

Tatar C, Bessert D, Tse H, Skoff RP. 2013. Determinants of central nervous system adult neurogenesis are sex, hormones, mouse strain, age, and brain region. Glia 61: 192-209.

* Toni N, Schinder AF. 2015. Maturation and functional integration of new granule cells into the adult hippocampus. Cold Spring Harb Perspect Biol doi: 10.1101/ cshperspect.a018903.

Touyarot K, Bonhomme D, Roux P, Alfos S, Lafenêtre P, Richard E, Higueret P, Pallet V. 2013. A mid-life vitamin A supplementation prevents age-related spatial memory deficits and hippocampal neurogenesis alterations through CRABP-I. PLoS ONE 8: e72101.

Tozuka Y, Fukuda S, Namba T, Seki T, Hisatsune T. 2005. GABAergic excitation promotes neuronal differentiation in adult hippocampal progenitor cells. Neuron 47: 803815.

Trejo JL, Carro E, Torres-Aleman I. 2001. Circulating insulin-like growth factor I mediates exercise-induced increases in the number of new neurons in the adult hippocampus. J Neurosci 21: 1628-1634.

Tronel S, Fabre A, Charrier V, Oliet SH, Gage FH, Abrous DN. 2010. Spatial learning sculpts the dendritic arbor of adult-born hippocampal neurons. Proc Natl Acad Sci 107: $7963-7968$.

Tropepe V, Craig CG, Morshead CM, van der Kooy D. 1997. Transforming growth factor- $\alpha$ null and senescent mice show decreased neural progenitor cell proliferation in the forebrain subependyma. J Neurosci 17: 7850-7859.

Van Praag H, Kempermann G, Gage FH. 1999. Running increases cell proliferation and neurogenesis in the adult mouse dentate gyrus. Nat Neurosci 2: 266-270.

Van Praag H, Shubert T, Zhao C, Gage FH. 2005. Exercise enhances learning and hippocampal neurogenesis in aged mice. J Neurosci 25: 8680-8685.

Villeda SA, Wyss-Coray T. 2013. The circulatory systemic environment as a modulator of neurogenesis and brain aging. Autoimmunity Rev 12: 674-677.

Wagner JP, Black IB, DiCicco-Bloom E. 1999. Stimulation of neonatal and adult brain neurogenesis by subcutaneous injection of basic fibroblast growth factor. J Neurosci 19: 6006-6016.

Wang S, Scott BW, Wojtowicz JM. 2000. Heterogenous properties of dentate granule neurons in the adult rat. J Neurobiol 42: 248-57.

Wang LP, Kempermann G, Kettenmann H. 2005. A subpopulation of precursor cells in the mouse dentate gyrus receives synaptic GABAergic input. Mol Cell Neurosci 29: $181-189$.

Winner B, Cooper-Kuhn CM, Aigner R, Winkler J, Kuhn HG. 2002. Long-term survival and cell death of newly generated neurons in the adult rat olfactory bulb. Eur $J$ Neurosci 16: 1681-1689.

Wise PM. 2003. Creating new neurons in old brains. Sci Aging Knowledge Environ 2003: PE13.

Wolf SA, Kronenberg G, Lehmann K, Blankenship A, Overall R, Ramirez-Rodriguez G, Müller A, Melnik A, Waltinger TP, Ullrich O, et al. 2006. Cognitive and physical activity differently modulate disease progression in the amyloid precursor protein (APP)-23 model of Alzheimer's disease. Biol Psychiatry 60: 1314-1323.

Wolf SA, Bick-Sander A, Fabel K, Leal-Galicia P, Tauber S, et al. 2010. Cannabinoid receptor CB1 mediates baseline and activity-induced survival of new neurons in adult hippocampal neurogenesis. Cell Commun Signal 8: 12.

Wolf SA, Melnik A, Kempermann G. 2011. Physical exercise increases adult neurogenesis and telomerase activity, and improves behavioral deficits in a mouse model of schizophrenia. Brain Behav Immun 25: 971-980.

Yeung ST, Myczek K, Kang AP, Chabrier MA, Baglietto-Vargas D, Laferla FM. 2014. Impact of hippocampal neuronal ablation on neurogenesis and cognition in the aged brain. Neuroscience 259: 214-222.

Zhao C, Teng EM, Summers RG Jr, Ming GL, Gage FH. 2006. Distinct morphological stages of dentate granule neuron maturation in the adult mouse hippocampus. $J$ Neurosci 26: 3-11.

Zhu Y, Demidov ON, Goh AM, Virshup DM, Lane DP, Bulavin DV. 2014. Phosphatase WIP1 regulates adult neurogenesis and WNT signaling during aging. J Clin Invest 124: 3263-3273. 


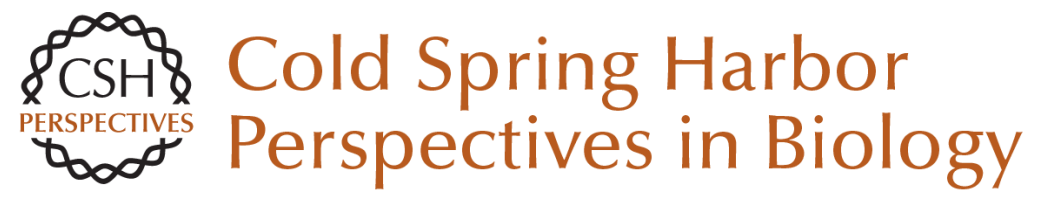

\section{Activity Dependency and Aging in the Regulation of Adult Neurogenesis}

Gerd Kempermann

Cold Spring Harb Perspect Biol 2015; doi: 10.1101/cshperspect.a018929

Subject Collection Neurogenesis

Adult Neurogenesis and Psychiatric Disorders

Eunchai Kang, Zhexing Wen, Hongjun Song, et al.

Neuronal Circuitry Mechanisms Regulating Adult

Mammalian Neurogenesis Juan Song, Reid H.J. Olsen, Jiaqi Sun, et al.

Neurogenesis in the Developing and Adult Brain

- Similarities and Key Differences

Magdalena Götz, Masato Nakafuku and David Petrik

Genetics and Epigenetics in Adult Neurogenesis Jenny Hsieh and Xinyu Zhao

The Adult Ventricular-Subventricular Zone (V-SVZ) and Olfactory Bulb (OB) Neurogenesis Daniel A. Lim and Arturo Alvarez-Buylla

Diversity of Neural Precursors in the Adult Mammalian Brain

Michael A. Bonaguidi, Ryan P. Stadel, Daniel A. Berg, et al.

Detection and Phenotypic Characterization of Adult Neurogenesis H. Georg Kuhn, Amelia J. Eisch, Kirsty Spalding, et al.

Maturation and Functional Integration of New Granule Cells into the Adult Hippocampus Nicolas Toni and Alejandro F. Schinder
Adult Olfactory Bulb Neurogenesis

Pierre-Marie Lledo and Matt Valley

Adult Neurogenesis in Fish Julia Ganz and Michael Brand

In Vitro Models for Neurogenesis Hassan Azari and Brent A. Reynolds

Engineering of Adult Neurogenesis and Gliogenesis

Benedikt Berninger and Sebastian Jessberger

Computational Modeling of Adult Neurogenesis James B. Aimone

Control of Adult Neurogenesis by Short-Range Morphogenic-Signaling Molecules Youngshik Choe, Samuel J. Pleasure and Helena Mira

Adult Neurogenesis: An Evolutionary Perspective Gerd Kempermann

Epilepsy and Adult Neurogenesis Sebastian Jessberger and Jack M. Parent

For additional articles in this collection, see http://cshperspectives.cshlp.org/cgi/collection/

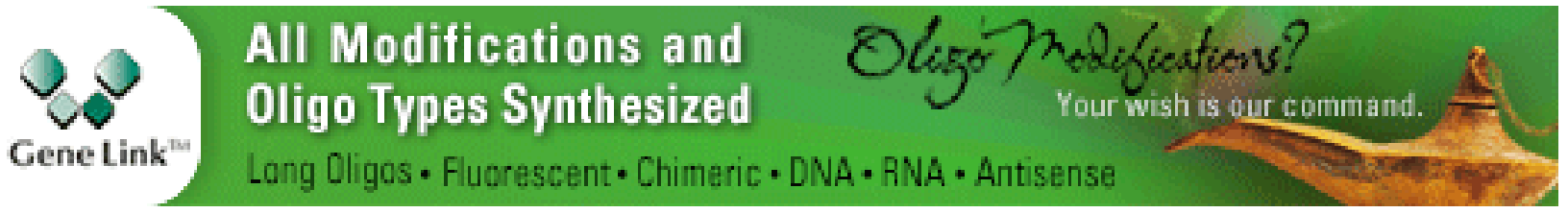


For additional articles in this collection, see http://cshperspectives.cshlp.org/cgi/collection/

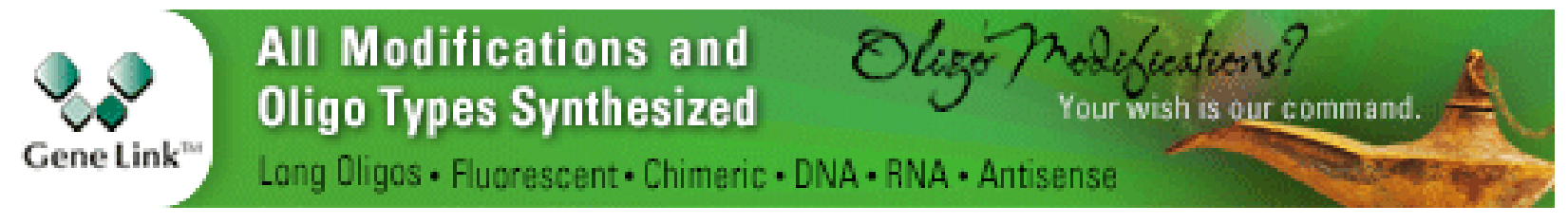

Copyright @ 2015 Cold Spring Harbor Laboratory Press; all rights reserved 